\title{
A DECISION ANALYSIS OF THE OIL BLOWOUT AT BRAVO PLATFORM
}

\author{
David W. Fischer
}

$$
\text { January } 1978
$$

Research Memoranda are interim reports on research being conducted by the International Institute for Applied Systems Analysis, and as such receive only limited scientific review. Views or opinions contained herein do not necessarily represent those of the Institute or of the National Member Organizations supporting the Institute. 


\section{Copyright (C) 1978 IIASA}

All rights reserved. No part of this publication may be reproduced or transmitted in any form or by any means, electronic or mechanical, including photocopy, recording, or any information storage or retrieval system, without permission in writing from the publisher. 


\section{Preface}

This case study is part of a larger effort devoted to the study of certain environmental measures connected with oil development in the North Sea. In turn this research subject has been part of the programme management task in the Management and Technology Area at IIASA. The results of this case study signalled the beginning of a new research task, that of disaster management once a major technological system goes out of control. 



\section{Summary}

The oil blowout problem has received increasing attention as the search for oil has been carried further offshore. Most scientific effort has been on the prevention side via predictions of blowouts and changes in design of the platforms. Few studies has focussed on oil blowouts once they have occurred.

This paper is a case study of the oil blowout that occurred on the Bravo platform in the Ekofisk field in the Norwegian sector of the North Sea. The primary data included interviews with the group who directed the Norwegian government response to this blowout. Other data came from preliminary reports made available soon after the incident.

The paper describes the physical aspects of the blowout and the existing principles that guided the initial responses from Phillips Petroleum and Norway. These principles are subjected to a critique prior to the description and structuring of the alternatives facing Phillips and Norway as they responded to this crisis.

The government actors involved in the blowout response and their roles are also briefly described. Finally, the decisions made by the Norwegian Action Group are classified and described. Following this effort a qualitative evaluation is offered of these decisions.

\section{Acknowledgements}

The author wishes to thank Hans Chr. Bugge, the Director of the State Pollution Control Authority and the Action Group at Bravo, for his valuable comments during interviews and in reading the original draft. All responsibility for the contents here rests, of course, with the author. 
. 


\section{CONTENTS}

Page

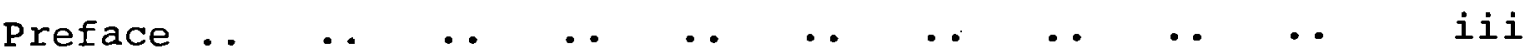

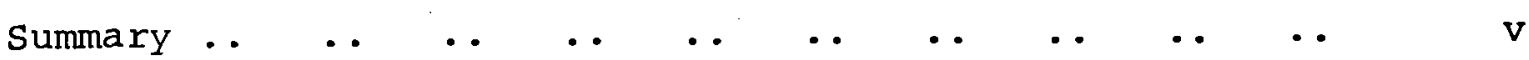

Acknowledgements $\ldots \begin{array}{lllllllll} & \ldots & \ldots & \ldots & \ldots & \ldots & \ldots & \ldots & \end{array}$

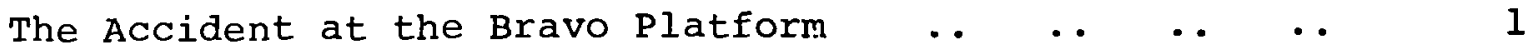

The Principles Established Before Bravo $\ldots \ldots \ldots$... 3

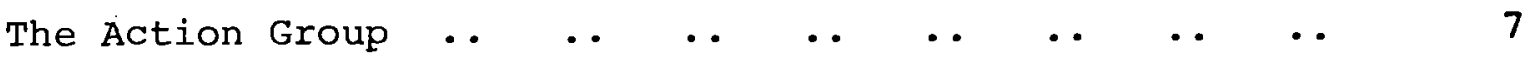

The Alternatives Facing the Action Group $\quad \ldots \quad \ldots \quad \ldots \quad 11$

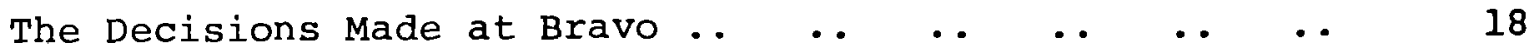

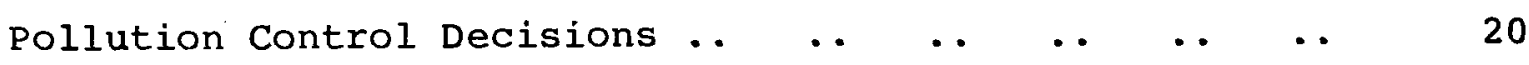

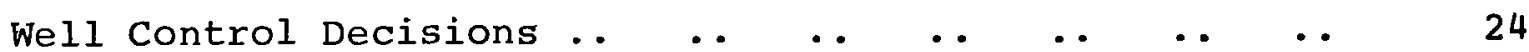

Evaluation of the Bravo Responses $\ldots \ldots \ldots+\ldots 26$

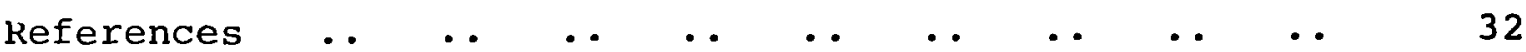



A Decision Analysis of the

Oil and Gas Blowout at Bravo Platform

On April 22, 1977, an offshore oil well went out of control that signalled to the North Sea oil industry and governments and, indeed, to the rest of the world that the North sea had now come of age in joining other oil producing areas in experiencing a major blowout. From this time to the regaining of control of the Bravo well of the Ekofisk field on April 30 a maximum of 21,300 tons of oil escaped from the well. [1] This escaped oil represents revenue loss to both the oil company owning the well and to the Norwegian government owning the subsea shelf, utility loss in the products and services foregone, potential and actual damage to the marine environment, financial loss in meeting the emergency itself, and possible compensation to any injured parties.

\section{THE ACCIDENT AT THE BRAVO PLATFORM}

The blowout at the Bravo offshore well occurred while maintenance work was being undertaken on a production well on a platform housing fourteen other wells. While the automatic blowout preventer valves worked on these other wells the well under maintenance went out of control. The specific causes of this blowout were investigated by an independent commission set up by the Norwegian government. Their report was submitted on october 10 , 1977. [2] Any combination of causes including also prediction of subsurface conditions, poor well design, poor crew training and ineffective supervision by company and government personnel can be involved. [3] However, at Bravo platform the underlying cause of the blowout was found to be the organizational and administrative systems being inadequate to assure a safe well workover operation. [4]

A comment attributed to Red Adair, the famed tamer of oil wells while he was in Norway after tending to the well at Bravo, notes that he has tended to more blowouts caused during the repair or maintenance of production wells than from the drilling of exploration wells. His statement was corroborated by the Bravo Commission Report:

"A well workover is a major task that is performed comparatively rarely. Experience shows that the blowout hazard is greater for such work than for any other work performed on the field in the production phase." [5]

Such statements conflict with the generally held Norwegian view that exploration wells have the highest blowout potential. [6] Certainly, there is a need for better accessible records on the occurrence and causes of blowouts. 
This study, however, does not focus on the cause of the blowout or on its prevention. Rather the emphasis is on the management of the crisis itself after the blowout occurred. While attention of analysts has been directed to risk assessment of possible blowouts [7] less effort has been spent on the management of such blowouts once they occur. The coping strategies employed in an emergency situation can often reveal the priorities of the core actors in their specific responses to a specific situation. Indeed, not only are the priorities revealed but the alternatives taken as well as those rejected can reveal the way in which the decision process operates. Thus, this section does not attempt to detail the actual and pending impacts from the Bravo blowout but instead seeks to outline the roles of the actors involved, the alternatives seen as feasible and the decisions actually taken. Where possible some evaluation is made of these decisions.

The blowout at Bravo consisted of a maximum of 2,830 tons of oil and 1,410 tons of gas per every 24 hours for almost eight days. [8] No completely accurate measure of these oil and gas losses is available. Foreign matter in the formation itself or in the production pipe could have reduced the flow of oil and gas. Fress reports at the time of the incident noted figures varying from 4,000 to 7,000 tons of oil per day which exceeded the company stated theoretical maximum; however, no bases were given for such figures.

The escaping mixture is of a light consistency forced through the well head at a near boiling temperature and under extraordinarily high pressure. The mixture shoots above the platform in the form of a spray where a portion of the oil is evaporated before it contacts the water surface. The gas, of course, is nearly entirely evaporated. As the oil is spraying out of the well head it is being mixed with water from the spray of a fire boat to prevent the hot oil from starting a fire or the gas igniting an explosion which could destroy the platform.

The resulting oil slick formed on the waters surrounding the Bravo platform was brown in colour and 1-2mm thick. The mixing action of the winds and waves as well as the water spray from the fire vessel caused emulsifying conditions to occur changing the colour and composition of the slick. The assumption of the Action Group is that $50 \%$ of the blown-out oil evaporated into the atmosphere while natural degradation of the remaining oil emulsions caused the slick to disintegrate. The size of this intermittent slick covered an area of approximately $4000 \mathrm{Km}^{2}$ in varying degrees of thickness and contamination in Norwegian waters with only a small portion reaching into the Danish sector. The slick did not move toward the coast as initially feared but remained in the general vicinity downwind from the blowout source through the combined effect of the winds and currents. The movement of invisible dissolved oil beyond this area is unknown. The rate of spread of the main slick was less than one $\mathrm{Km}$ per hour. Observations from daily air flights showed that the slick was relatively stationary and would eventually become completely 
disintegrated under natural weather conditions. Few lumps were expected to reach the Norwegian coast, the area of greatest potential damage.

Not only was the Bravo incident the first major blowout in the North Sea but it was also the first major oil loss in the Norwegian sector. Previous incidents had only occurred in the UK sector from tankers as well as minor incidents from platforms. Therefore, no experience had yet evolved in Norway for responding to emergencies connected with large offshore oil spills. This lack of experience' is not to say, however, that Norway was not prepared or expecting such emergencies. It simply had not dealt with the actual problems surrounding these offshore incidents.

\section{THE PRINCIPLES ESTABLISHED BEFORE BRAVO}

The government of Norway had ostablished certain principles for dealing with emergencies connecteü with offshore oil development in the North Sea before the Bravo incident. [9] These principles can be summarized under four headings:-

1. principles for operator:

- assignment of responsibility to the operator where the operator must be able to meet every situation which might occur,

- requirement to keep available the most advanced technology at any time for meeting these situations,

- assignment of unlimited liability to the operator for all damages and costs resulting from the situation,

- requirement for an operator's plan for meeting possible situations as they may arise.

2. principles for regulator:

- approval of operator plans and operations through the respective expert agencies coordinated by the oil Directorate of the Ministry of Industry and Crafts,

- government superceding operator when operator deemed unable to handle the situation or the risk of great damage is present,

- creation of regional emergency response centers along the coast and subsidization of municipalities for responding to emergencies to supplement operator efforts.

3. principles for well control:

- prime emphasis on saving human life, e.g., ensuring the safety of platform workers, 
- stopping the uncontrolled flow of oil at the well head as the main objective in combatting a blowout.

4. principles for pollution control:

- operator containing and capturing the oil slick as near as possible to the source of flow, e.g., clearing the oil in the open sea,

- emphasis on mechanical means for stopping oil pollution rather than using chemical dispersants,

- government participation in research and development on such mechanical means,

- national government responsibility for protection of the coastline on a cost recovery basis from the operator.

The Bravo incident provided the first real test of the practicality of these principles. While many of these principles seem to be obvious some of them carry implications that a priori would appear to affect the adequacy of response by both operator and regulator.

The assignment of initial responsibility to the operator to be able to meet every situation which might occur and with the most advanced technology is in reality constrained by economics. The operator generates its own response system for meeting this principle governed by its cash flow position. Offshore operators therefore rely primarily on prevention technology rather than on oil clean-up technology. To avoid the financial losses associated with oil losses in the first place is an objective overriding in importance the clean-up of such oil once it is in the sea.

Given the secondary importance of clean-up it is not surprising that operators would not invest heavily in advanced clean-up technology. First, the operators rely on one automatic blowout preventer valve 50 meters below the seabed and another manually activated at the wellhead. These valves were considered failsafe by both the oil industry and the government regulators involved. [10] Second, the operators rely on chemical dispersants which are acceptable to the UK government, but currently not to the Norwegian government. The operators' assumption seemed to be that in the final analysis Norway would allow the use of chemical dispersants rather than accept coastal damage from oil pollution. Certainly, chemical dispersants are effective in reducing possible economic liability for the operator since they remove the oil from the surface. Third, the operators rely on industry experts in stopping blowouts who are not resident to the North Sea area. No retainer is paid to these experts to maintain a presence in the vicinity, therefore it must be assumed that it is cheaper to have an ad hoc outside well control response rather than to develop an internal well control capability or to maintain a regular local response capability of the outside experts. Finally, the operators assume that their prevention technologies so limit the probability of blowouts that given the 
government's position of overriding the operator at any time it is cheaper to pay the government on a cost recovery basis for clean-up than to invest heavily in advanced clean-up technologies themselves which could then go unused, eventually become obsolete through advanced design or prove unworkable. These suggestions appear to be valid reasons why the operators do not invest in advanced oil pollution clean-up technologies even though the Norwegian government acts on the assumption they do so.

With little economic incentive existing for operators to fully comply with the implications of this principle of initial responsibility the government also has problems with this principle. Through primary reliance on the operator to prevent and respond to blowouts the government would not a priori rapidly build up a large response capability itself. Other more immediate demands on the government budget could intervene to reduce the kind of supplementary response necessary. Thus, the government could be forced to rely on outside exlerts and the oil industry itself since it would not have the of information base to form its own adequate and sustained response to a blowout. This situation can set the stage for a crisis approach to blowouts rather than a rational response. However, only elements of this problem existed as the Norwegian government haa created and approved a coastal response programme and funded it at an adequate level for completion in Spring 1978, a year after the Bravo blowout occurred.

The principle of unlimited liability also carries with it an economic constraint since there is some economic limit to operator liability. Operators insure their blowout risk by spreading such risk with insurance companies which in turn spread their risk among still other insurance companies. Insurance companies have some risk limit of liability based on their assessments of the risk involved and the laws governing such risk. There is a 1974 agreement limiting liability for damages from each incident to $\$ 25$ million, although Norway does not recognize this limit. At present operators accept this limit, but nine European governments are attempting to ratify another agreement raising this limit to $\$ 35$ million and then to $\$ 45$ million five years later. [11]

Thus, the government cannot assume there is no ceiling to the liability of the operators of its oilfields. In other sense, the final liability of damages from a blowout rests with the owner of the seabed, the government representing the country of Norway. Any other countries sustaining damages from a blowout in the Norwegian sector of the North Sea may have the right to seek compensation from Norway itself or one of its national organizations, particularly since Norway through statoil is becoming an operator in its own right as well as being a majority owner of fields operated by private companies.

The principle of maintaining the most advanced response technology is subject to economics as well. At any point in time the operator as the choice of opting for stocking existing 
technology or waiting for another advance in technology before choosing a particular design. With the above principle no guidance is given to the operator for making this choice although a penalty seemingly accrues should the wrong choice be made by opting for a given technology too soon. The basic guidance available is from the manufacturers of such technologies who are prone to exaggerate the performance characteristics of their respective designs. For example, in the Bravo incident the skimmers used proved only $25 \%$ effective of their claimed capacities which are determined for ideal conditions which rarely exist. [12] An operator can also decide between undertaking its own research programme in clean-up technology or investing in a given technological design. Once an operator has invested in a given design it has an incentive not to continue in research which would render its own investment obsolete before its payout period.

This technology problem becomes more acute when coupled with the lack of any means to really meet a blowout and to clean-up oil pollution from such a blowout. As the government admits: [13]

- "The operators have little equipment with which to meet a major blowout. Under the existing rules the operators are required to have such equipment, but the authorities have not yet imposed specific requirements . . ."

- "However it is clear that no mechanical means are available at present which would be effective under the conditions of wind and sea prevailing in the areas under consideration. Therefore requirements relating to dispersants must also be imposed."

- "If a blowout should occur there would not be enough chemicals in the North Sea area for effective oil spill treatment."

Given these statements it was obvious to both operators and government that the existing emergency plan was in reality a good intention rather than an actual means for controlling and cleaning up blowouts. In this case it would not be surprising that emergency plans of offshore operators were inadequate and that this inadequacy was well known to the government authorities. Thus, it is possible that since such plans were not really capable of being adequately fulfilled they were not given strong credence in the drilling permit or well programme approval process. However, the government did approve a set of specific requirements in the Summer of 1976 for equipment and gave the operators one year to meet them.

The principle of relying on mechanical means for responding to oil pollution on the sea instead of the cheaper and proven chemical dispersants was not well received by the oil companies because of the greater possibility for liability for damage, the 
greater expense involved, the lack of proven effectiveness of such means and the lack of definition of "best available". Also the UK was committed to chemicals in its producing sector of the North Sea. Nevertheless, the Norwegians continued to hold out for primary reliance on the mechanical means of booms and skimmers to contain and capture the oil slick even though these means were known to be inadequate in the open sea. Because of genuine operator skeptism little company research was done on mechanical means, although BP in the UK had developed a skimmer for use in the high seas. Thus, the Norwegian government was almost alone in relying on the principle of mechanical means which meant that its effectiveness had to be proven by them even though the operators in theory were to maintain the most advanced designs in such means.

A large government research programme was not forthcoming, although some funds were allocated to private manufacturers for research on such devices. No trainj.ry programme for boom and skimmer operators existed. Oniy limited funds were allocated to municipalities for purchase of mechanical means to protect their shoreline. The demonstration effect of this government effort was not lost on the oil companies who tended to continue to delay on the necessary investment. At the time of the Bravo incident, however, the government and the oil companies had agreed on a mechanical design and orders had been given for such devices by both the government and the operators.

The underlying principle for responding to an oil blowout for both prevention and control can be conveniently summarized: the Norwegian regulators rely on the self-interest of the operator to handle the blowout problem, e.g., they base much of their regulatory activities on the operator's own supervision of its oil exploration and production activities. [13.5] Such a system of supervision requires a good and continuing knowledge of the operator's supervisory capability and their plans and alternative responses to expected and unexpected events.

The discussion of these principles is designed to suggest the context in which the Bravo incident occurred. The "criticism" implied in the discussion of these a priori principles in no way apply to the response to Bravo by the operator or the government.

\section{THE ACTION GROUP}

Any crisis brings about a coalition in what would normally be seen as a diverse and disassociated set of actors. These connections between apparently separate actors readily become visible in the case of the Bravo incident, and a system of actors with shared interests is demonstrated in the response to this crisis. [14] The existence of the Bravo problem provided not only a means to temporarily bring diverse actors together to end the crisis but it also threatened future offshore oil development north of $62^{\circ}$ in Norway and future regulations for such development by other countries in offshore areas. 
The core actors included the Action Group as key regulator. The ,Action Group was an ad hoc response since it was not in existence prior to the blowout, although it had been under active consideration for some time before Bravo. [15] This Group was created by the Environment Minister about six hours after the blowout occurred. The Group was given the necessary ad hoc authority from the government to expend monies and commit the government to whatever actions and expenses deemed appropriate in responding to the Bravo crisis. If feasible major problems were to be presented to the Minister for decision. Four days later on April 26 a permanent Action Group was formalized by Royal Decree for maintaining a quasi-permanent response mechanism for such accidents.

The Action Group's composition was based on the assumed needs of the situation at Bravo: [16]

- measures to control oil pollution - State Pollution Control Authority

- measures to control oil flow - Oil Directorate

- provision of transportation and personnel - Navy

- provision of rescue and safety - Police.

Leadership was assumed by the Director of the State Pollution Control Authority who reported directly to the Minister of Environment. One representative from Phillips Petroleum was liaison to the Action Group. Had a tanker oil spill been involved the Marine Directorate would have been involved instead of the oil Directorate. Later a representative from the Ministry of Foreign Affairs who specialized in handling information for the foreign press was attached as liaison.

The Action Group performed in a reticulist role [17] because it was a focal point representing five different policy systems, three within the national government, one from local government and the private operator. This reticulist group acted as an assessor of the blowout situation at the interface of the broad development and environment policy systems. The major difference in the definition of the reticulist role is that the Action Group had decision authority granted to it by the Minister of Environment which affected all policy systems represented. The judgements of this Group, however, were carried out through the respective organisations for the actions desired, therefore the Action Group represented the hub of the decision network.

The Action Group's tasks were to assist Phillips Petroleum to control the oil flow at the well and to create a back-up response for controlling and cleaning up the oil pollution from the well. The Action Group's first priority was to aid Phillips to stop the uncontrolled flow of oil. This task was under the direct supervision of the Oil Directorate representative and carried out through Phillips Petroleum, owner and operator of Bravo platform. The Action Group had no direct responsibility 
for the operations at Bravo; rather it surveyed and controlled the measures suggested by the operator. [18]

The next priority came under the aegis of the State Pollution Control Authority representative which involved alerting other North Sea countries as well as coastal communities in Norway and preparing a response to capture and contain the oil slick before it reached the coastline. This effort was accomplished through direct supervision of an ad hoc government containment exercise involving a variety of personnel, equipment and vessels from many different areas.

After being formed the Action Group was faced with deciding what to do. Several key alternatives were open to the Action Group, including the timing of implementation of such alternatives.

The first set of alternatives centered around the organisation of the Action Group in relation to other governmental bodies as well as to Phillips Petroleum. Figure 1 shows the relationship of the Action Group to other important organisations associated with Bravo. As is readily seen the Action Group played the central and authoritative role in combatting the oil blowout of Bravo.

The Action Group checked Phillips' plans for dealing with the blowout and its resulting pollution. Afterward Phillips was asked to prepare a new plan to meet the additional criteria decided by the Action Group. This draft plan was prepared and presented to the Oil Directorate who checked this draft for its technical aspects. Then Phillips presented these revised plans to the Action Group for approval. The Oil Directorate representative corroborated their feasibility, and the Action Group approved the plans. A constant monitoring of Phillips' operations was also undertaken.

The Action Group also closely monitored the oil pollution containment effort of Phillips as it did with the well control problem. The Action Group and Phillips worked out a containment plan and implemented it through the Navy as the on-the-scene supervisor. A variety of groups and equipment were coordinated and united into responding to the oil pollution.

The other role envisaged for the Action Group consisted of its being solely a coordinating group. This coordinating role would have allowed Phillips Petroleum and the Oil Directorate to assume more leading roles in the response to the blowout. In this case the government would have been in a passive position responding to initiatives from Phillips. In addition, emphasis would have been on controlling the blowout with a lesser effort on its resulting pollution. Violation of established government principles would also have been possible.

The direct authoritative role taken by the Action Group stemmed from the established principle that the government can take over the operation if it deems that the risk of great damage 


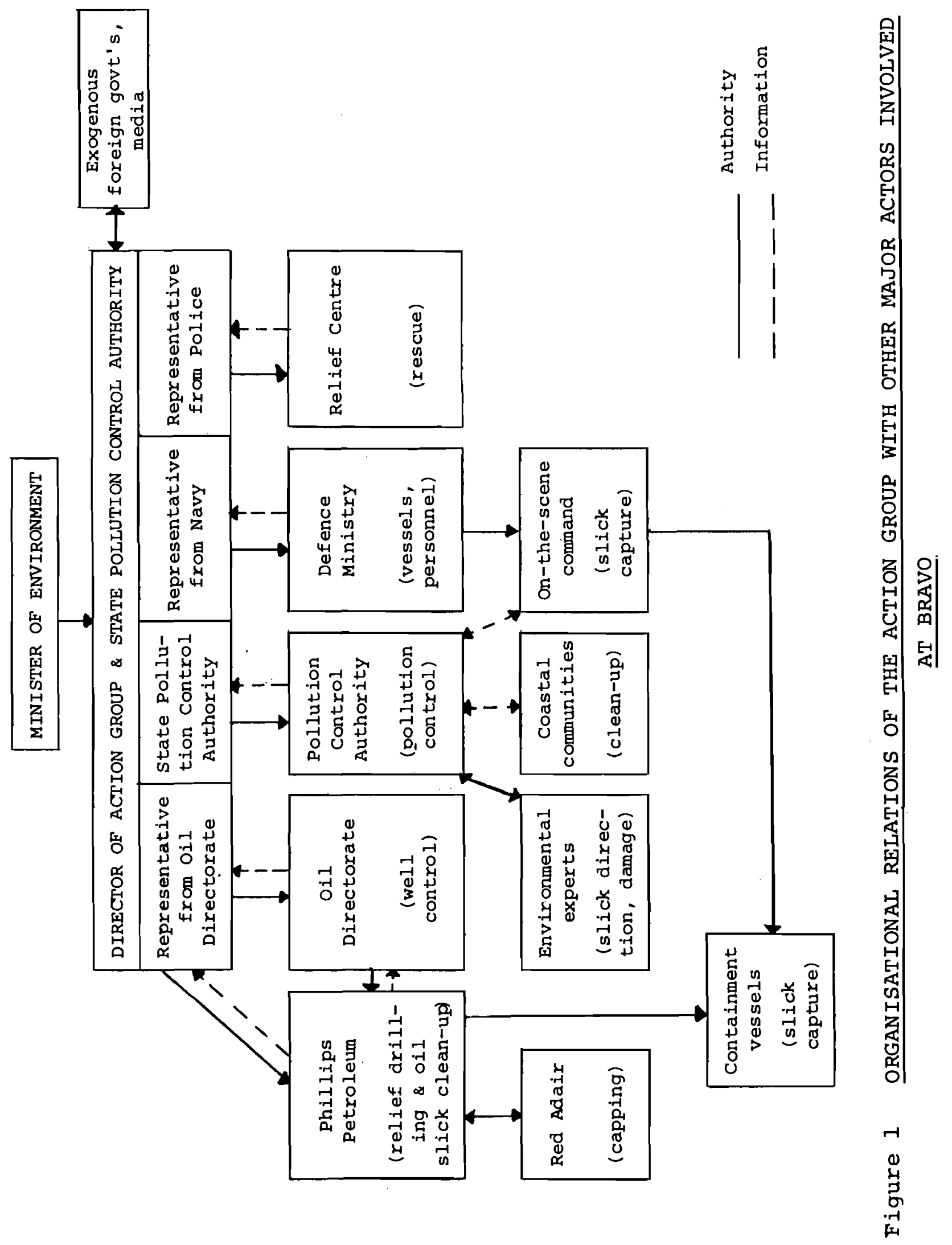


is present. [19] Thus, the operator was aware that the government could take over the company operation at any time. During the time prior to the formation and take over by the Action Group Phillips Petroleum was already engaged in employee rescue, fire prevention, spraying with chemical dispersants and assessing well capping possibilities.

\section{THE ALTERNATIVES FACING THE ACTION GROUP}

The general flow of operations and allocation of resources to prevent and control an oil blowout as well as contain its oil slick is shown in Figure 2. This generalized scheme represents the stages in an oil blowout from its initial prevention to its final absorption into the natural environment. Between each stage is the flow of oil that escapes the previous effort in attempting to stop that flow. At each of these stages environmental impacts occur from this escaped oil. The amount of oil escaping with its resulting environmental impact is directly correlated with the amount of resources allocated to these stages to reduce the escape of such oil. Any oil blowout programme requires resources to be allocated for prevention, control and anti-pollution efforts at any one time in order to minimize environment impacts from oil blowouts and pollution. Over-concentration of limited resources in any one area will leave the rest of the system at a disadvantage with respect to unprevented, uncontrolled or loose oil in the environment.

From this more general system alternatives can be displayed for prevention, control and retarding pollution. Figure 3 shows key prevention alternatives which were to have been in place prior to the Bravo blowout. Since the blowout occurred the prevention system used was not failsafe. Although this study does not discuss the prevention system per se it is of interest to briefly show its usual extent. [20]

The prevention system begins with well planning which includes careful interpretation of the strata to be penetrated. From this interpretation and prediction come the well location, design and drilling programme. The latter stresses the equipment to be used, the casing size and depths, the drilling mud programme and any specialized training necessary for the operators. The well operation is based on effective supervision and continuous monitoring of the drilling process. Monitoring consists of lowering a device into the well to assess the drill bit as it cuts and analysing the drill cuttings and drilling mud at the surface as they circulate back from the drilling. Well maintenance is an especially important time as the drill string is pulled as well as the casings which retain the shape of the shaft. Mud flow and density are of particular importance at this time to maintain the well's pressure balance. Finally, should the well pressure begin to go out of balance during drilling or maintenance a rapid adjustment in the drilling valve can be activated either automatically or manually to shut down the well should the well pressure become too great too quickly to adjust the mud flow. 


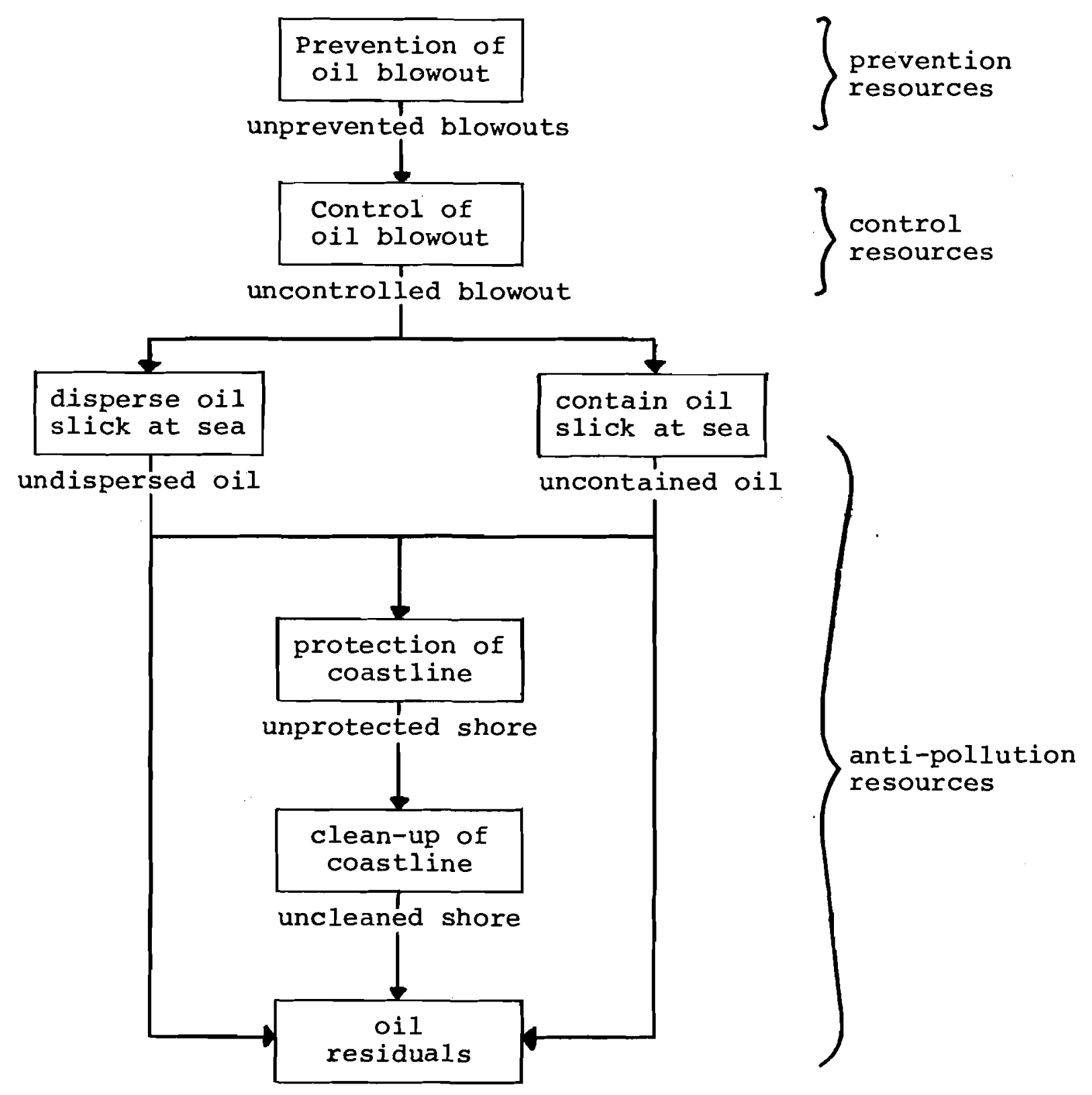




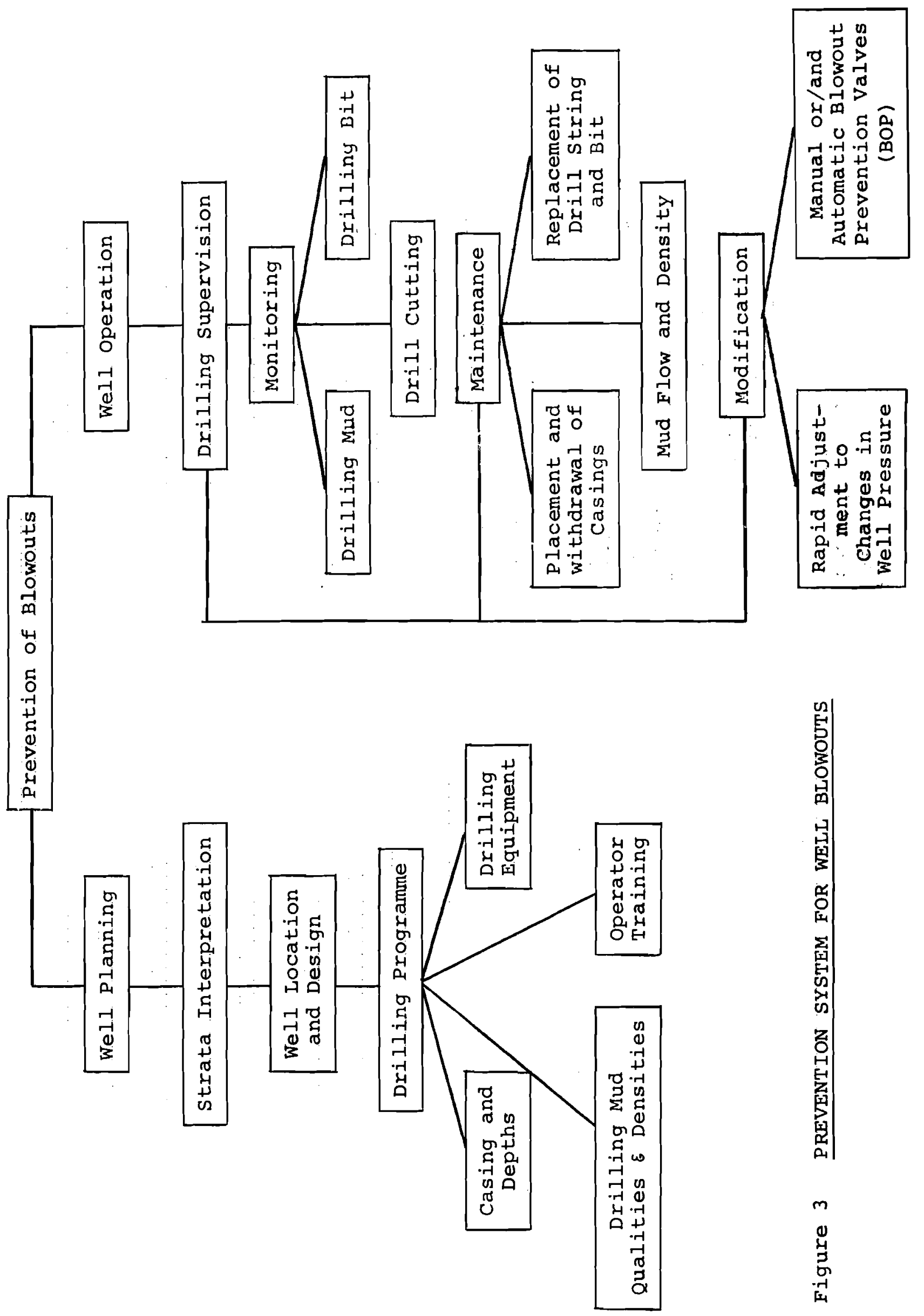


Should a blowout actually occur regaining well control becomes of paramount importance. Figure 4 outlines the consecutive steps required for attempting to regain well control, e.g., obtain pressure control. The first line of defense consists of the blowout preventer valves (BOP), the automatic subsea BOP valve and the manual surface BOP valve. Should these BOP valves not work mud pumping must be stepped up to regain control of well pressure; indeed mud pumping begins as soon as well pressures begin to rise and before the manual surface BOP valve must be shut. At the same time a fire prevention spray programme is begun to dampen the rig and allow shut-off of all wells on the rig. Rescue of rig personnel also occurs at this point so that the use of BOP valves, pumping of drilling mud, other well shutdowns on the rig, fire prevention and personnel rescue are all occurring at relatively the same time.

After the rig is abandoned to the oil blowout from the uncontrolled well then work commences on a capping operation. The capping effort can be initially carried out by the operator but usually outside experts are called in to attempt to cap the blowout. Either simultaneously with capping, in lieu of capping or if capping fails a relief well must be drilled near the uncontrolled well to pump mud into the oil reservoir. If this drilling effort fails then the well continues out of control in a blowout condition until all of the oil and gas is burned out.

While this well control effort is underway work is simultaneously begun on combatting the oil pollution spewing from the well. The basic principle governing this anti-pollution work is to capture as much of the oil as is possible nearest the point of loss. [21] The alternatives open to meeting this spreading oil pollution threat are shown in Figure 5. The first three alternatives of disperse, contain or destroy are open for a decision-maker because natural decomposition is continually occurring. Destruction of the oil slick is only possible for minor oil spills because of the difficulties of applying these measures and their dependence on weather, location, degree of concentration of oil slick and materials readily available.

The two basic alternatives for major oil spills include its dispersal or containment. Both of these alternatives have opposite effects so that one cannot be effectively used if the first employed does not work. Although dispersants can be applied at any time they are the most effective when the oil is fresh; therefore, a decision to attempt to contain and capture the oil slick is to forego effective chemical dispersal. Each of these two alternatives has special problems in their application. The main disadvantage associated with dispersants is their high possible impacts on the marine environment. Even given this possibility, however, these chemical dispersants have "been the most employed on the Norwegian continental shelf". [22] Their wide use stems from their advantages of rapid deployment, reasonable effectiveness under navigable weather conditions, relatively low capital cost and lack of need for trained operators. 


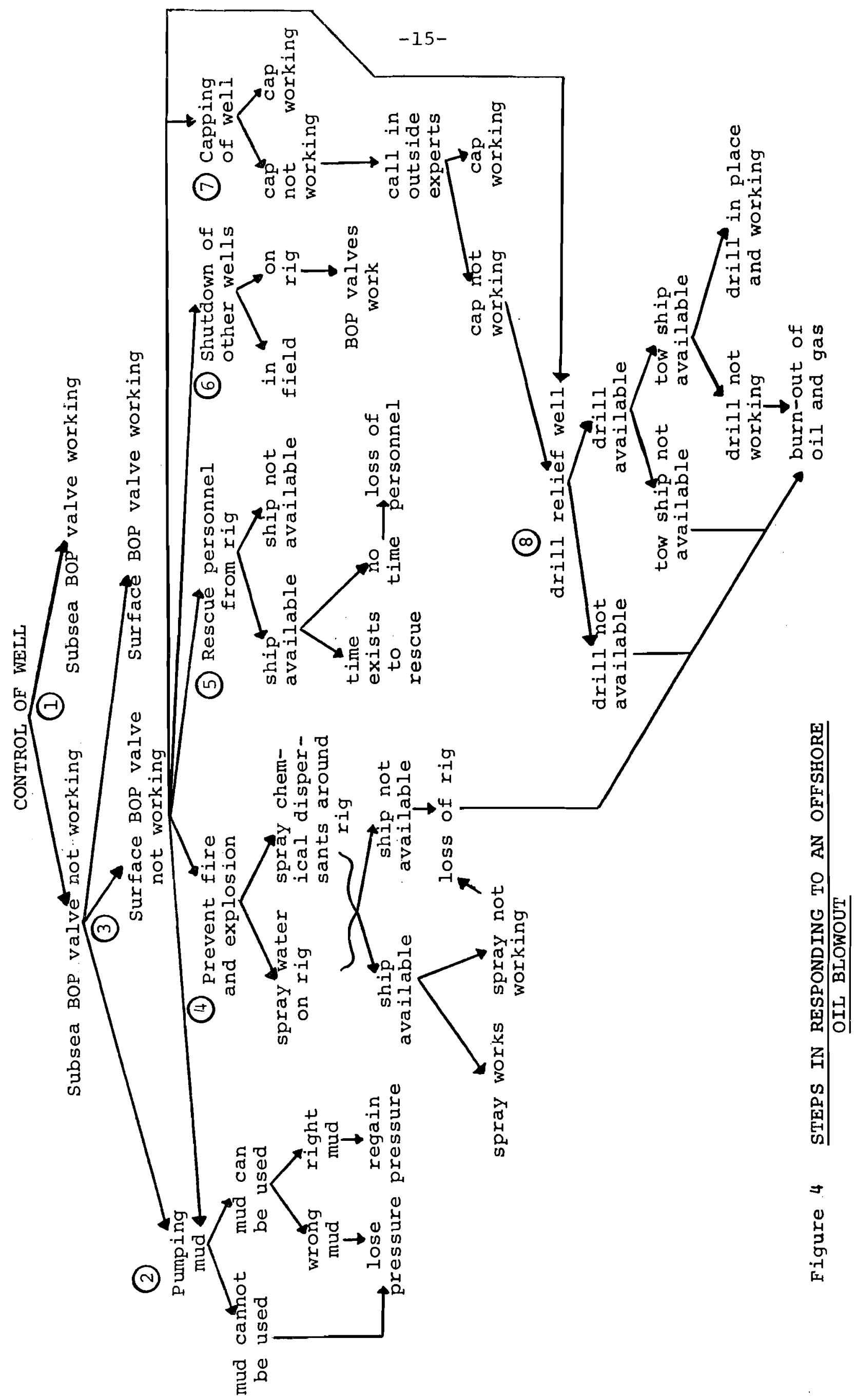




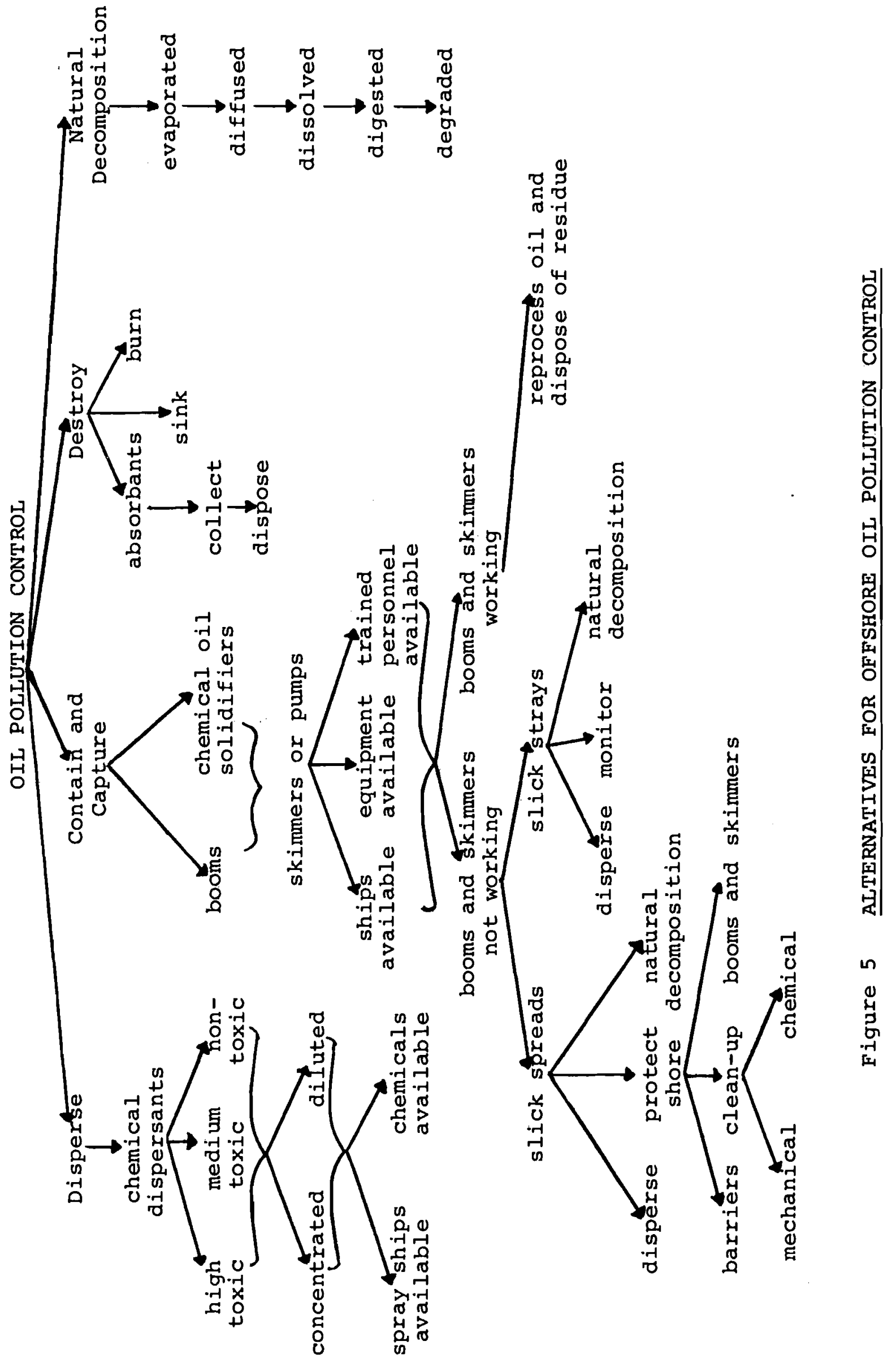


The advantages of chemical dispersants are the exact disadvantages of mechanical containment and capture of oil slicks. Mechanical systems are difficult to mount, ineffective under moderately bad weather conditions, have high capital cost and require trained operators. Even though these disadvantages are present mechanical systems continue to be of interest because of their advantages of "removal of pollution potential, no ecological consequences, claimed high and sustained recovery rates and relatively low operating costs". [23]

Spill size and location as well as wind and current direction are the crucial factors in deciding which of these two basic alternatives to employ. These factors are of importance even if the general principle of reliance is on one system or the other.

Shore protection is important because the coastal zone is the area of greatest potential ecological damage. Also, the costs of shore clean-up after the oil reaches the coastline are very high because of its labour intensity. Therefore, the emphasis is on dealing with the oil slick before it reaches coastal waters. The key trade-off here is oil on the shore versus chemicals in the sea.

Some sequencing of these alternatives is important. Directly around the source of the oil blowout chemical dispersal is necessary to remove the fire hazard to the offshore platform. At sea either dispersants or containment can be used, while inshore barriers, containment and clean-up are required.

The alternatives and resources for blowout prevention, well control and pollution control and clean-up have been presented in the last three figures. These alternatives have been displayed to show what the Action Group could have decided upon in their attempt to meet the Bravo blowout. However, another series of "alternatives" are important in their determining the appropriate responses, particularly for well and pollution control. This array consists of the alternative events that could have taken place at the time of the blowout at Bravo or if the blowout had occurred at another location and time. Table 1 lists the major events that are possible to occur in a North Sea oil blowout situation.

While it would be of interest to construct a decision and events tree, none of the events in Table 1 actually took place during the Bravo oil blowout. In fact, in the judgement of the Director of the Action Group, the response to Bravo was already at the limit. Had any combination of these events been present or coupled with the responses chosen much greater difficulties and damage would have characterized the Bravo blowout. clearly, the Bravo event in itself provided a valuable "training exercise" for future blowouts under more adverse conditions. 
Table 1 POSSIBLE EVENTS INFLUENCING THE RESPONSES TO AN OFFSHORE OIL BLOWOUT

\begin{tabular}{|c|c|}
\hline PROBLEM & POSSIBLE EVENTS \\
\hline $\begin{array}{l}\text { Well } \\
\text { Control }\end{array}$ & $\begin{array}{l}\text { Blowouts from other wells on rig } \\
\text { Fire and explosion on rig } \\
\text { Loss of rig in explosion } \\
\text { Casing ruptured below sea level } \\
\text { Subsea well blow away from rig } \\
\text { Prolonged stormy weather } \\
\text { Winter darkness } \\
\text { Towing and placement of relief rig }\end{array}$ \\
\hline $\begin{array}{c}\text { Pollution } \\
\text { Control }\end{array}$ & $\begin{array}{l}\text { Another blowout elsewhere in North Sea } \\
\text { Prolonged stormy weather } \\
\text { Strong inshore currents } \\
\text { Winter temperature increases brittleness of booms } \\
\text { Winter darkness } \\
\text { Migration times and routes } \\
\text { Spawning times and sites }\end{array}$ \\
\hline
\end{tabular}

THE DECISIONS MADE AT BRAVO

The decisions made at Bravo are significant in establishing the major outline of Norwegian responses to oil blowouts in future. Principles of operation were both established or confirmed by these decisions. The basic decisions listed in this section were provided by the Director of the Action Group as well as from the preliminary report by this Group to the Minister of Environment. Figure 6 shows the outline of these decisions based on this information.

The first major decision was the appointment of the Action Group by the Minister of Environment, including the necessary authorization to make decisions in the name of the Norwegian Government. This decision, of course, was basic to the entire operation associated with Bravo. The government provided its backing to the Action Group where the Minister of Industry and the Minister of Environment worked together in support of it. Thus, the leading government representatives of the development and environment policy systems were in unity in responding to the Bravo crisis. The Director of the Action Group was also the 


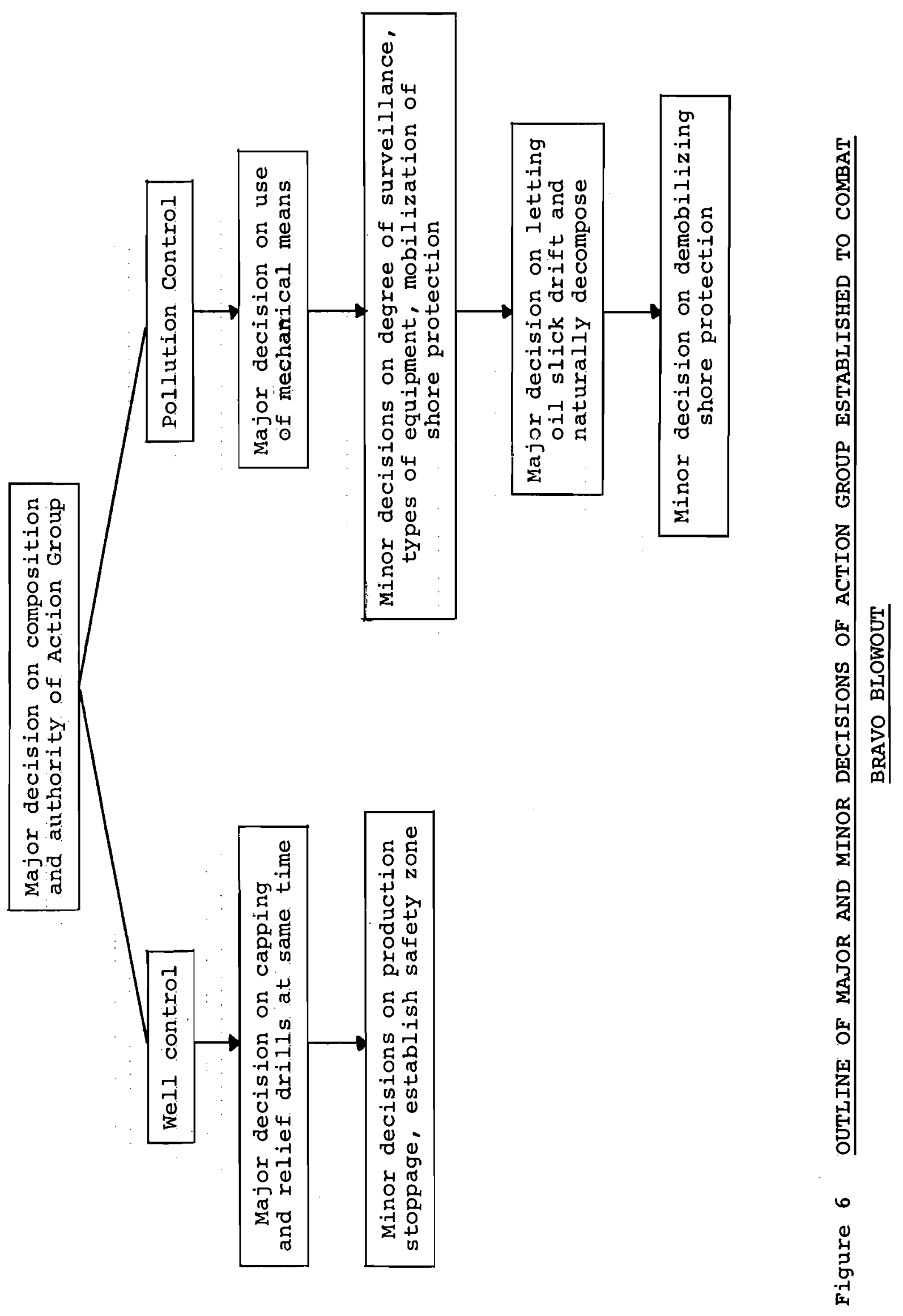


Director of the State Pollution Control Authority so that the Group functioned under the immediate direction of a representative from the environment policy system who, in turn, reported directly to the Minister of Environment. Therefore, while a union between government development and environment core actors existed, the environmental actors were in the lead role. The basic premise was that the Bravo blowout was a national emergency requiring a unified national response. The idea of a coordinating Action Group was rejected as too passive and reactive in favour of a Group capable of being unified around actions stemming from their own assessments and decisions. This key decision of authority and and unity centered in an ad hoc Action Group is central to the entire Bravo response. This initial decision was further corroborated by the government when it established the Action Group as a permanent body days later. [24]

The implication of this decision was not only to guarantee a unified response in the government but also to establish a command relationship with Phillips Petroleum. Under previous principles Phillips as owner and operator of the Bravo platform was considered totally responsible for the blowout and for meeting the crisis brought on through their operation. Phillips was to take whatever steps were necessary to stop the blowout and to restrict the damage from the blowout. In addition, Phillips had accepted unlimited liability, including liability for actions made by the government in its response. This liability posture was reconfirmed by the Action Group.

What had not been decided or known prior to Bravo was whether the operator or the government would take the lead role in the response to the crisis. All that had been known a priori was that the government could take over the management of the crisis if the situation demanded it. No guidelines existed to define these circumstances. The government, in accordance with this established principle, decided immediately to take over the entire operation and to direct Phillip's responses to the blowout. Thus, the company became subordinate to the government even though the company was to both carry out the work and pay for the entire operation.

\section{POLLUTION CONTROL DECISIONS}

The second major decision emerged from the authority assumed by the Action Group in relation to Phillips. This decision involved the total reliance on mechanical means to stop oil pollution rather than rely on chemical dispersants. Much of the time of the Action Group was spent in discussing this issue. It was finally referred to the Minister of Environment for final approval because of its signal importance. This decision had implications for the size and degree of the effort and hence expense necessary to combat oil pollution, the increased risks of oil reaching the coastline through the delay of getting mechanical devices in place and their unproven operational feasibility, and the precedent for future operations connected 
with major oil spills. Political risk was involved as Norway has a strong political orientation to its fisheries and fishing industry. The judgement of "no chemicals" meant continued political support for the established principle of mechanical containment.

In its investigation of Phillips' plans and actions the Action Group found that Phillips had no mechanical equipment or trained personnel for same on hand either offshore or in Norway. In fact, Phillips had only chemicals available for meeting oil pollution from its offshore platforms; therefore, the operator had relied solely on chemical means for dispersing oil pollution. The reliance on chemicals may be seen, however, as an interim measure until phillips was able to comply with government regulations passed in November 1976 to have on hand an oil pollution clean-up capacity of 8,000 tons per day. The blowout occurred in the delay between the government passing the regulation and having it implemented by the operatois. [26]

The first twelve hours after the blowout Phillips had been using chemicals freely in its effort to disperse the oil. Phillips only stopped when ordered to do so by the Action Group the day after the blowout. [27] Around the platform, however, Phillips was allowed to continue to use chemicals to disperse oil to reduce fire hazard. As a back-up measure Phillips was also allowed to bring chemicals and spray vessels out to the area for eventual use if deemed necessary by the Action Group. Phillips requested the Action Group to approve its plan for a combined use of mechanical and chemical means; however, after a discussion with scientists and other experts the use of chemicals continued to be prohibited.

Since the Action Group placed total reliance on mechanical means several other lesser decisions and efforts became important. These more minor decisions involved the degree of accuracy of surveillance and forecasting of the decomposition and movement of the oil slick, the types of mechanical means to use in the attempt to collect the oil, and the mobilization of a coastal protection effort.

Two flights were made daily to observe and photograph the oil slick. In addition, a naval vessel was dispatched to take charge of the collection effort and to report on the decomposition, spread and movement of the oil slick. Also Phillips mounted its own aerial effort to document the development of the slick. The method that evolved consisted of having an aircraft follow the contours of the oil slick while being traced on the radar by the navy command vessel in the vicinity.

The key problems involved in these surveillance efforts were the number of aircraft from other nations involved in monitoring the oil slick and the thinning and patching of the slick itself over time. During Norwegian air surveillance at any one time Swedish, Danish, German, English and NATO aircraft could be in the vicinity plotting their individual estimates of the movement 
of the slick. Inevitably these estimates were not in total agreement but more importantly air traffic control became a problem through differences in the definition of a safety zone over the platform vicinity. The gradual thinning, spreading and break-up of the slick into patches meant that to maintain the initial degree of accuracy greater surveillance effort would have to be mounted. The Action Group decided not to attempt to maintain the same element of accuracy but to describe the slick in more general terms.

The next minor decision proved to be of considerable difficulty, that of what types of booms and skimmers to employ. Whatever mechanical equipment available in Norway for use on high seas was flown into the Action Group's center of operations. Both Phillips and Norwegian aircraft and vessels were used in transporting the booms and skimmers to the site of operation. In addition, two Swedish coast guard vessels with booms and skimmers were requested to work at Bravo. Many other offers of equipment were received by the Action Group from many foreign sources. The Group decided to reject these offers and stick with the equipment it knew best as it could only concentrate on what it already knew. Norway had already developed coastal protection booms and had tried them in the open seas in good weather. other equipment had been ordered but never tested.

The greatest problem area in the use of the equipment employed was the gap in performance between that stated by the manufacturer and that observed in actual use. Equipment with a theoretical capacity of picking up 7,000-8,000 tons of oil per day, which exceeded the estimated flow of oil from the blowout, only collected 20 tons of oil the first day of its actual use. [28] Thereafter, the equipment was reported to be $25 \%$ effective under the most ideai conditions. Other equipment having a 4,000 ton rating collected oniy 100 tons in a day. Equipment used by Phillips having a capacity of 1,800 tons a day also proved to be $25 \%$ effective. Four Vikoma skimmers developed in the UK by BP and employed by sweden had a theoretical capacity of 300 tons per day each but only collected 60 tons in total during the time they were used.[29] The only skimmer that collected oil as rated in the open seas with ninefoot waves had been designed and built in Norway but never tested prior to its actual use. In all, eight different types of booms were tried and three types of skimmers.

The emulsified oil collected by this equipment totalled $1,700 \mathrm{~m}^{3}$ which contained $935 \mathrm{~m}^{3}$ of pure oil (about 800 tons). The greatest amount collected in a single day was $800 \mathrm{~m}^{3}$ while the least collected was $60 \mathrm{~m}^{3}$. [30] The total amount of 800 tons of collected pure oil, of course, cannot begin to compare with the maximum total of 21,300 tons of oil which escaped through the blowout (only $3.7 \%$ of oil collected). Although waves were high and the weather considered bad for booms and skimmers conditions under which the equipment was used were not completely out of line since stormy conditions were not prevalent. Most of the equipment simply failed to work in the open sea under less than ideal conditions. [31] 
Another problem with this equipment was the sheer number of many small units to be brought together and actually deployed in an effective manner. Transport, booms, skimmers and personnel had to be found and matched to form an effort capable of containing and collecting the oil. For example, four boats could be required for 500 meters of boom: one at each end of the boom, one to collect the oil and one to take it away. If 10,000 meters of booms are used the sheer number of boats becomes very difficult to control. Also some vessels had maintenance problems, others had insufficient crew and still others were too underpowered to remain in place in high seas. Booms and skimmers of one design were difficult to put into place and match with other designs. Insufficient numbers of effective booms and skimmers were available to be used even if conditions were ideal. The heavier slick approximated 1,500 square kilometers in area and only 6,100 meters were actually put to use or on stand-by. Phillips ordered 2,000 meters of booms but only 100 meters per day could be produced. Finally, personnel were generally liritrained in the use of such equipment. A learning period was necessary in order for personnel to learn to use the equipment effectively. Differences in opinion existed over whether the equipment was ineffective in itself or rendered ineffective through inadequately trained personnel. At present an assessment is underway to determine the extent of effectiveness of the equipment, vessels and communciations used.

The coastal protection mobilization effort was the final minor decision connected with the major decision to reject chemicals in favour of mechanical collection. The coastal communities were informed by the state Pollution Control Authority that an oil slick was approaching the Norwegian coast. The oslo center of the Agency acted to coordinate the community efforts in protecting their respective shoreline. Communities were to review their resources, establish emergency plans and specify areas to be protected. The government also guaranteed to cover any expenses for establishing emergency measures and participation in protection and clean-up efforts. No purchase of equipment was guaranteed. This latter decision may have stopped some communities from ordering equipment that would have competed with the production capacity geared to the more immediate equipment needs at sea. Although oil had at first been expected to reach the coast by April 26 it was not until May 2 that the entire coastal area to be affected was organised. Some criticism was put on the national government by these communities but the Bravo blowout showed that these communities were generally ill-prepared to respond adequately to the coastal oil-threat.

The other major decision associated with the pollution control effort involved letting the oil slick just drift and naturally decompose at sea with no effort to mechanically collect or chemically disperse this slick. This decision was in one sense a "non-decision" in that the Action Group did not want to ignore the slick. The decision was necessitated by the sheer impossibility of coping with the slick via mechanical means. Once the slick began to thin out and break up into isolated patches over such a wide area of the sea it became too expensive an operation for the 
given effectiveness of the mechanical devices used. Therefore, the combined ineffectiveness of the oil collection equipment with the cost of mounting the required extensive attempt to collect the oil became deciding factors in letting the slick drift. Added to these two factors was the prognosis that the slick would remain at sea, naturally disintegrate and not touch the coastline. Finally, only a chemical dispersant effort would approach cost-effectiveness at this stage and such a means had already been ruled out, although chemicals may have been used if the slick had approached the shore.

The mixing action of the sea continually caused the oil slick to evaporate and disintegrate. On May 3 it was estimated that in another five to six days the oil would be completely disintegrated; therefore, the final minor decision was the demobilization of the coastal protection effort on that same day. Some risk was involved in this decision but weather forecasts and the slick movement and decomposition forecast were such that the effort of maintaining a major state of readiness was not worth the cost of this effort.

\section{WELL CONTROL DECISIONS}

The other major decision that stemmed from the authority given to the Action Group in relation to Phillips was associated with well control. Phillips was ordered to both present a wellcapping plan and to start drilling a relief well at the same time. [33] such an ad hoc well control operation was necessary because no plans for how to handle an uncontrolled well were available in either Phillips or the Oil Directorate. [34]

On its own initiative Phillips called in the assistance of the Red Adair Company from the us who are industry experts in controlling oil blowouts. It took 24 hours for the team to arrive and be on the Bravo platform. During the approximately 36 hour period since the blowout began nothing was done to attempt to control the flow of oil. Since the general industry view is that each blowout is unique [35] well control procedures do not seem to be in evidence once a blowout has occurred.

With the assistance of the Red Adair Company representatives Phillips' engineering staff developed a plan for the capping procedure. Both the Oil Directorate and the Action Group approved the Phillips-Adair plan. The plan was difficult to implement because the surface BOP valve was installed upside-down. [36] This reversed position forced an improvisation of the equipment used to cap the well. After several unsuccessful tries another improvisation worked to close off the well and allow the pumping of mud to stablize the well pressure. When finally brought under control on April 30 at 17.45 hours the well had been in a state of uncontrol for nearly eight days, spilling up to 21,300 tons of oil into the North sea (although the actual amount may be less). 
Simultaneously with the capping operation Phillips began the search for a rig to be towed to the Bravo site and used to drill a relief well. Such a well is used to relieve the pressure build-up in the reservoir; therefore, it must be close to the uncontrolled well. Two days after the blowout began a jack-up rig was found and put under contract to be moved; however, the poor weather conditions would not allow the removal of the rig. After nearly four days of repeated attempts to remove the jack-up rig Phillips was ordered by the Action Group to bring in a semisubmersible rig in addition to the jack-up rig already under contract. A semi-submersible rig was located and was to arrive on site on May 1. Since the blowout was stopped on April 30 Phillips requested permission to cancel the two relief well contracts. The Action Group approved this request 15 minutes after the Oil Directorate declared that the blowout was stopped. [37]

Qualitative differences exist between the two rigs contracted for. The jack-up rig has the advantage of being able to be jacked up adjacent to the uncontrolled well thoreby ensuring that it will relieve the blowout pressure. Its disadvantages include the requirements for good weather and a stable seabed for placement. The semi-submersible rig overcomes the disadvantages of the jackup rig but its disadvantages is the length of distance from the blowing well when it is placed on site. The distance is such that its ability to relieve the reservoir pressure is more uncertain.

Stopping production of oil and gas from the remaining wells on the Bravo platform was automatic through their BOP valve systems. Stopping production of oil and gas on the entire Ekofisk field, however, was a matter to be decided. Rules were in existence for stopping such production but only under weather conditions of wind velocity and direction or under certain gas concentrations. Oil blowouts were not included in this original criterion and the Oil Directorate had not decided whether or not the field should be shut down during a blowout. However, the Action Group established its own criteria for stopping production based on fire risk which was agreed to by Phillips. Production was actually stopped several times due to adverse weather conditions.

The government decided on its own counsel to stop all production from the Ekofisk field independent from the Action Group's criteria. [38] The Action Group and the Oil Directorate were informed by their respective Ministers after the decision had been made. While the Action Group had once discussed this issue, neither the Action Group nor the oil Directorate had been consulted in advance of the government's decision. Technical reasons were not the basis for the decision but rather it was a political decision. It showed to Norwegians that the government was taking some action in the crisis. Once the well was brought under control the entire Ekofisk field was under production again within four hours. 
The last minor decision in regard to well control was the establishment of a safety zone around the blowing well at Bravo platform. This zone was established for safety reasons to ensure good working conditions around the platform and to avoid the possibility of other accidents in the immediate area. The zone provided by the Continental Shelf Convention was defined as a free space 500 meters' radius from the platform and with no air space restrictions above it. Creation of this safety space provided some difficulty to foreign observers in aircraft, particularly to the media and press reporters, because the Action Group defined the zone in wider terms. The zone was established on a ten nautical mile radius and a ban was placed above the platform to 5,000 feet. Different national definitions of national air space where unilateral decisions can be made make the creation and recognition of such zones difficult. Clarification of the air space issue with respect to such zones in future is a matter that is to be pursued. [39]

\section{EVALUATION OF THE BRAVO RESPONSES}

Evaluation of the activities and decisions surrounding the Bravo incident is made on several bases. Included in this evaluation are the lessons learned by the Action Group itself, the comments from critics and observers, and the criteria posited by the author.

The Action Group, formed for the first time to be the focal point of the responses to Bravo, learned many lessons in its short exposure to the blowout. This experience is summarized below in point form: [40]

- Organizational evaluation:

1. the authority given the Action Group was confirmed as the best organizational form;

2. the creation of an industry disaster advisory body to the Action Group was also seen to be useful;

3. the fact that oil companies have different responses to blowouts between countries was discovered, e.g., in the UK companies have formed a clean seas Committee to act as a clearing center for cooperation whereas in Norway no such body exists nor did the other oil companies provide help to Phillips;

4. the experience showed that no common approach to blowouts exists between countries in the North Sea area;

5. the need is seen for specialist companies such as the Red Adair Company to allow government observation of their work and to cooperate more fully with the government. 
- Information evaluation:

1. the recognition was made of the need for more reliable information on the performance of mechanical means of pollution control in the open sea under a variety of weather conditions;

2. the need for a special VHF disaster communications channel was seen as a necessity since the Action Group had to rely on other emergency frequencies normally required for rescue purposes;

3. the need for greater research on the effects of large amounts of oil in the water column was seen as important for damage prediction and assessment.

- Equipment evaluation:

1. the recognition of a lack of options was seen as a problem so there is a neea for the government and the oil industry to develop options to allow blowout management;

2. the need is seen for a failsafe design on the manually operated BOP valve, e.g., it should work even in a reversed direction or be impossible to fit in a reversed position;

3. the need is also seen for a completely new approach to pollution control in the open sea via mechanical means, e.g., this approach should work close to the blowout source, have a large capacity in all weather conditions and be a single self-contained large unit;

4. the necessity to adopt a training program for operating fire prevention, capping and pollution control equipment is seen as important;

5. the need is seen as evident that standards be adopted for pollution control equipment on a uniform international basis.

The Action Group's assessment of itself is an important starting point in the learning process surrounding the Bravo event. The Director of the Action Group felt that Norway was quite fortunate in the timing of the blowout and in the prevailing weather conditions during this time. Had the blowout occurred earlier it would have affected a major migration of birds (Alkes) and had it occurred later a major spawning ground of fish (Mackerel) would have been directly affected. It also came at a time when daylight was present during most of the operation over a 24-hour period and reasonable weather conditions were prevalent.

The greatest surprise to the Director was the failure of the booms and skimmers to even approach their specified capacities of clean-up. Clearly, there was much to be desired in the testing and rating of the specifications of such equipment. Beyond this major discrepancy in performance, however, he sees a need for a better approach based on the principles of containment and capture. 
The greatest satisfaction to the Director is that during the entire response to the crisis no loss in human life or property resulted. Platform personnel, capping personnel, anti-pollution personnel, surveillance personnel and foreign observers all were able to successfully carry out their assignments with no loss in life. In addition, the platform and equipment work in these operations did not suffer extensive damage or loss.

Since both Norway and the UK have the major petroleum development programs in the North sea it is of interest to compare their planned responses to sudden oil losses. Both countries have attempted to exchange information on their respective efforts, including cooperation on protection of the sea from oil spills. [41] In a major UK report the following qualities are identified for meeting oil spills: [42]

- authority to act in a defined sphere of jurisdiction,

- leadership and direction,

- knowledge and expertise,

- access to resources,

- plan of action, and

- good communications.

In Norway's response to the Bravo blowout the Action Group created by the government met and appeared to excel at most of these criteria. What the Action Group lacked was in having knowledge of pollution control equipment's peformance in the high seas, a pre-arranged plan of action and good communications links to the field. These needs are now recognized and are to be developed.

Both the UK and Norway hold to the principle of the industry being liable for the costs of dealing with an incident, including meeting overhead costs of the clean-up effort and depreciation on equipment. [43] The major difference is that the UK has agreed to a ceiling on liability whereas Norway only recognizes unlimited liability. Both countries also hold that the industry is responsible for cleaning up oil spills offshore and that responsibility only shifts to government when the public interest is at risk through inability of the operator to cope, or the use of poor treatment methods or some oil escapes and threatens the coast. [44]

Major differences in the UK and Norwegian responses seem to be in four areas:

- In the UK no statutory obligations exist for anyone to clear up oil spills or to prepare plans to do so. [45] Norway has a requirement for spill clean-up and the preparation of plans to do so.

- In the UK it is not even known if contingency plans for spills exist since there is no requirement for such plans to be created or approved by government. [46] 
Norway requires such plans as part of the basis for issuing an exploration license and drill permit.

- In the UK primary reliance for combatting oil spills is on the spray of an approved chemical dispersant of low toxicity. [47] Norway has preferred to rely on mechanical means even though such means are known to be ineffective in the open sea.

- In the UK primary reliance is made on local authorities to define their degree of response by deciding for themselves what values to place on their coastline and what effort should be made to clear it. [48] Norway takes a national stance of protection of its coastline even though each local area must carry out the clean-up of its own area.

The report referred to in the $z$ w ve quotes does suggest, however, that operators should develop an action plan for each offshore installation along with a "dedicated and adequately equipped anti-pollution stand-by vessel permanently on station at each group of production platforms". [49] Also these action plans should be submitted to the government for approval and involve interested government bodies in their preparation. Finally, such action plans should be coordinated among operators. Some convergence is thus anticipated in the positions occupied by these two countries as the complexities of petroleum development in the North sea mount.

Two striking phenomena are the uncertainties with pollution control equipment performance and with damages sustained from the slick. If one were to predict areas where knowledge should have been available prior to the Bravo incident, certainly one would have selected these two areas a priori. It was obvious, however, that research and development programs to ensure the existence of such knowledge were not adequate. Poor information existed on the actual performance of the booms and skimmers under a variety of weather conditions in the open sea and on the damages to be expected from a oil slick over time.

Most of the conflicts were subdued but centered on the pollution control operation rather than on well control. The basic conflicts were over chemical versus mechanical means and application of such mechanical means. Differences also existed over potential damages from the slick.

Clearly, the Bravo blowout will be a catalyst to signal changes in approach to pollution control in Norway, and perhaps in the entire North Sea area. The past design, present stress and future adjustment of the principles and plans of oil accidents are of major importance for all North Sea countries. Certain problem areas that need to be clarified include: 
- commensurability of risk:

The establishment of the Action Group was designed to minimize risk of mismanagement of the blowout by Phillips. In line with this approach the Action Group minimized risk in ordering Phillips to both cap the well and contract for a relief rig at the same time. However, the Action Group may have taken a risk in foregoing chemicals and letting the oil slick remain and drift given the lack of knowledge on the fate of oil in the sea. This risk may not be in line with the potential for damages to marine organisms at sea and coastal communities in both Norway and Denmark.

- commensurability for pollution control:

Norway required the use of mechanical means of a theoretical rated capacity even though adequate doubt existed for both the means and its performance. Thus, reliance is really on the self-cleansing capacity of the sea. This approach differs for chronic oil discharges where pollution control equipment is required even though the sea could more readily absorb this pollution.

- commensurability of liability:

Norway sees the operators as having unlimited liability for their operations; however, Norway is the owner of the seabed, joint owner of the oil and often a joint partner in the operation. Therefore, Norway may be jointly liable for pollution damage and could not then assume that a private operator's liability exceeds its own liability or is an adequate environmental safeguard.

- commensurability of information:

Full information on alternatives prior to an accident is the basis for adequate decision-making during a crisis. Information on effectiveness of means of pollution containment under expected operational conditions and subsequent damages was not available. Total reliance on equipment manufacturers for information would not seem in keeping with the risk. Total reliance on the UK Warren Springs Laboratory for information on chemicals would also seem to be foregoing alternative information gained through Norwegian testing.

- commensurability of supervision:

The sanctions and degree of supervision seem to be the same for each operating company regardless of its accident record or phase of operation. Since phillips had had two previous production accidents in the North Sea [50] and since it was undergoing a well workover after loss of a monitor into the well at Bravo greater government supervision would have seemed warranted. Believable sanctions such as prescribed and enforced shutdown times are also of importance in stressing safety. 
- commensurability of response:

Bravo showed that Norway was not well prepared to handle a blowout even though its response was quite reasonable. Prior to Bravo the Action Group did not exist, no adequate well control capability existed in Norway and reliance was on untested pollution control equipment in the high seas. This low-level response existed even though statistically Norway was overdue for a blowout.

- commensurability of cooperation:

Bravo showed that each North sea country relied on different means with different emphases that were not always compatible with one another's response. In addition, each country seemed to have a different assessment of the risk of blowouts and the resulting damages. Finally, commitment of one country's pollution control means leaves that country vulnerable to an oji accident in its own sector or from elsewhere. [51] A need exists for a compatible and integrated response system to oil accidents in the North Sea. For example, agreement on the amount of standby equipment that is readily available for loan and compatible would be valuable.

Company cooperation in the North sea did not seem to meet the stipulations of the clean seas committee formed by the companies to cooperate with one another during oil accidents. Nor are company responses similar in each North Sea country. An integrated network of compatible and dependable responses would seem important for both companies and countries of the North Sea.

Norway was the first country to establish a code of sare practice for offshore drilling in 1967 and the first country to take seriously pollution from offshore oil activity. [52] In 1977 Norway was the first country to receive a major oil blowout in the North Sea. Given the comprehensive environmental interest in Norway it is clear that even safer drilling conditions will evolve and be integrated into the offshore petroleum development program. Better oil disaster management practices will also evolve and contribute to better environmental safeguards, but it remains to be seen whether this evolving response will be truly comprehensive and integrated into an overall system. 
REFERENCES

[1] Action Group, Preliminary Report to the Minister of Environment, Government of Norway, based on unofficial translation, manuscript, undated.

[2] Commission of Inquiry, Uncontrolled Blowout on Bravo, 22 April 1977, Unofficial Translation, Preliminary Edition, Ministry of Industry, Oslo, October 10, 1977.

[3] A.W.J. van den Hoek, Drilling Well Control, UNEP Seminar with petroleum industry, Paris, March 1977.

[4] Commission of Inquiry, op. cit., p.4.

[5] Ibid., p.102.

[6] Ministry of Industry, Operations on the Norwegian Continental Shelf, etc., Report No. 30 to the Norwegian storting, (1973-74), pp.26-27.

[7] Council on Environmental Quality, OCS Oil and Gas: An Environmental Assessment, Volume 5, Analysis of oil Spill Statistics, U.S. Government Printing office, April 1974; Department of Environment, Accidental Oil Pollution of the Sea, Pollution Paper lso. 8, HMSO, 1976.

[8] Action Group, op. cit., p.21. These figures are based on information from Phillips, the oil company which owned and was producing from the well.

[9] Ministry of Finance, Petroleum Industry in Norwegian Society, Parliamentary Report No. 25 (1973-74), pp.37-38; Ministry of Industry and Crafts, Petroleum Exploration North of $62 \%$, Report No. 91 to the Norwegian storting (1975-76), pp.9-11, 41-52.

[10] See, for example, Department of Environment, op. cit., p.56. Also Norway requires a minimum of four such B.O.P. Valves. See Ministry of Industry and Crafts, Petroleum Exploration North of 620N, Report No.91 to the Norwegian Storting $(1975-76)$, p.45.

[11] Ian Mather, The observer, May 1, 1977, p.2.

[12] Ibid.

[13] Ministry of Industry and Crafts, Petroleum Exploration North of $620 \mathrm{~N}, \mathrm{pp} .49,50,48$.

[13.5] Commission of Inquiry, op. cit., p.95-96. 
[14] D.A. Schon, Beyond the Stable State, New York: W.W. Norton, 1971 , pp.39-42.

[15] G. Gjerde, "National Contingency Planning with Special Emphasis on Oil Pollution", paper presented to the Offshore Safety and Reliability Seminar, Norwegian Petroleum Society, Hemsedal, May 23-25, 1977, p.3.

[16] Ibid., p.1-3.

[17] J. Friend, J. Power $\varepsilon$ Co., J.L. Yewlett, Public Planning: The Inter-Corporate Dimension, London: Tavistock Institute, 1974 .

[18] G. Gjerde, op. cit., p.4.

[19] Ministry of Finance, Petroleum Industry in Norwegian Society, Parliamentary Report No. 25, (1973-74), p.37.

[20] Ministry of Industry, Operations on the Norwegian Continental Shelf, Report No. 30 to the Norwegian Storting (1973-74), pp.26-33; A.W.J. van den Hoek, Drilling Well control, UNEP Seminar with petroleum industry, Paris, March 1977. Council of Environment Quality, OCS Oil and Gas: An Environmental Assessment, Volume 1, U.S. Government Printing Office, April 1974, pp.162-172.

[21] Ministry of Industry and Crafts, Petroleum Exploration North of $62 \%$, Report No. 91 to the Norwegian Storting $(1975-76), \mathrm{p} .47$.

[22] Ibid., p.48.

[23] Department of Environment, Accidental Oil Pollution of the Sea, Pollution Paper No. 8, HMSO, 1976, p.91.

[24] Action Group, Preliminary Report to the Minister of Environment, Government of Norway, based on unofficial translation manuscript, undated, p. 5.

[25] Ian Mather, The Observer, May 1, 1977, p.1.

[26] Ian Mather, Oil Spill Control is a Disaster, The Observer, May 1, 1977, p.2.

[27] Action Group, ㅇp. cit., p.42.

[28] Interview with Dr. Hans Bugge, Director, Action Group and State Pollution Control Authority.

[29] Ian Mather, "Oil Spill is a Disaster", The Observer, May 1, 1977, p.2.

[30] Action Group, Preliminary Report to Minister of Environment, Government of Norway, op. cit. 
[31] Ibid; Ian Mather, op. cit.

[32] Ibid., p.50-51.

[33] Ibid., p.37.

[34] Commission of Inquiry, op. cit., p.92.

[35] W.H. van Eek, State of the Art of Environmental Conservation, Exploration and Production, UNEP/ISS 5/2, Industry Sector Seminar, Petroleum Industry, paris, December 6, 1976, p.9; A.W.J. van den Hoek, Drilling Well Control, UNEP Seminar with petroleum industry, Daris, March 1977, p.2.

[36] Action Group, op. cit., p.38.

[37] Ibid., pp.38-39.

[38] Ibid. , pp.9, 39-40.

[39] Ibid., p.41.

[40] Most of these points were obtained by interview with the Action Group. For a fuller treatment of some of these points see The Action Group, Parliamentary Report to Minister of Environment on the Bravo blowout, unofficial translation by British Embassy, Oslo, manuscript undated.

[41] Norwegian-British Meeting on North Sea: Increased Interest for Oil protection Cooperation, Environment News, No.2, 1977, Ministry of Environment, Oslo, p.5 (in Norwegian).

[42] Department of Environment, Accidental oil Pollution of the Sea, Pollution Paper No. 8, HMSO, London, 1976,

[43] Ibid., p.108.

[44] Ibid., p.113.

[45] Ibid., p.119.

[46] Ibid., p.26.

[47] Ibid., p.20.

[48] Ibid., p.120.

[49] Ibid., p.113.

[50] I.L. White, et. al., North Sea Oil and Gas, Norman: University of Oklahoma Press, 1973, pp.68-69. 
[51] Denmark's commitment of its total pollution containment equipment and vessel left it unable to cope with a 40 ton spill in its own waters during the Bravo incident.

[52] Ministry of Industry, Operations on the Norwegian Continental Shelf, etc., Report No. 30 to the Norwegian storting (1973-74), p.27. 